\title{
JOVENS, FEMINISTAS, EM MOVIMENTO: A MARCHA MUNDIAL DAS MULHERES NO III ACAMPAMENTO INTERCONTINENTAL DA JUVENTUDE
}

\author{
JULIA RUIZ DI GIOVANNI \\ sOF - Sempreviva Organização Feminista
}

Resumo: O propósito deste texto é aproveitar as questões suscitadas pela participação da Marcha Mundial das Mulheres no III Acampamento Intercontinental da Juventude. As atividades e as ações propostas pelas jovens feministas de todos os continentes revelaram que as experiências dessa nova geração política atualizaram e renovaram as questões fundamentais da organização dos movimentos feministas.

Palovras-chave: juventude, feminismo, nova geração política, movimento antiglobalização.

\section{Formação a céu aberto}

A importância do trabalho da Marcha Mundial das Mulheres em buscar trazer o feminismo para a construção do III Acampamento da Juventude, realizado no coração do Fórum Social Mundial, talvez só possa ser entendida na medida em que o Acampamento significou, para milhares de jovens, uma extraordinária experiência humana. Uma experiência capaz de marcar uma geração inteira, pela invenção de linguagens comuns feitas de lutas, de debates, de todas as formas e cores que a vontade de mudar o mundo pode assumir sob um calor de 40 graus, em uma "cidade das cidades" habitada por gente dos cinco continentes.

Quando soubemos que no Acampamento estava se organizando uma marcha criativa, que faria um percurso alternativo para juntar-se à marcha de abertura do Fórum, logo imaginamos que ali era nosso lugar. Estávamos certas. A Marcha da Diversidade contra a Guerra e Pela Paz, que saiu do Parque Harmonia rumo ao centro da cidade, foi um dos momentos mais coloridos e emocionantes da história dos três fóruns mundiais em Porto Alegre, e será por muito tempo motivo de orgulho para as mulheres que cantaram e dançaram conosco. O bloco da Marcha Mundial das Mulheres, incansável à frente da passeata, foi um daqueles momentos especiais em que a ação coletiva vale por dez oficinas de formação, especialmente para as jovens. Quantas delas, nesses tempos de tanta miséria e de tanto remédio para emagrecer, têm a oportunidade de sair na rua em bloco, batendo tambor e gritando gostosamente "SOMOS MULHERES E NÃO MERCADORIA!"?

Copyright (c) 2003 by Revista Estudos Feministas 
Ou "SE CUIDA SEU MACHISTA QUE A AMÉRICA LATINA VAI SER TODA FEMINISTA!"? Todas - as militantes da Marcha, as habitantes do Acampamento, as que chegaram desavisadas saíram daquela marcha um pouco mais feministas do que entraram.

Além do bloco na marcha, organizamos duas oficinas na 'Cidade das Cidades'. Vale lembrar que o Acampamento (como o FSM gostaria de ser) é todo espaço: alamedas, gramados, terreiros a serem tomados pelas atividades políticas, lúdicas, culturais - às vezes por tudo isso ao mesmo tempo. Esse cenário não é irrelevante para o desenrolar dos debates, sendo de grande valor para a construção da presença da Marcha Mundial das Mulheres nos Fóruns e no movimento de movimentos e para que estejamos prontas a aproveitar de forma criativa momentos em que a falta de paredes e microfones se torna um recurso e não uma limitação.

\section{Onde estão as jovens feministas?}

Nas sociedades excludentes e opressivas em que vivemos no mundo todo, em que são bloqueadas desde muito cedo as condições das pessoas de transformarem suas histórias e realidades coletivas, em que a própria revolta e as aspirações de liberdade da juventude são esvaziadas de seu conteúdo político, muitas jovens não chegam a experimentar nem a necessidade das análises de gênero. Os discursos triunfalistas convencem multidões de que as mulheres 'conquistaram seu espaço'. Em todo lugar 'especialistas' despejam teorias sobre o desejo da mulher e a qualidade dos nossos orgasmos. Floresce uma parafernália de produtos e serviços dedicados ao nosso bemestar, à nossa nova individualidade, nosso tipo de pele, de cabelo, às nossas supostas aflições cotidianas e novas necessidades de consumo.

Cada vez mais a ação das mulheres e nossa sexualidade são seqüestradas pela linguagem da publicidade, direta ou indiretamente substituídas pelo consumo, pelo comportamento contemplativo e pela reprodução dos modelos apresentados pela mídia. Como podemos encontrar a coragem de fazer política e ainda por cima nos meter a feministas, nós que crescemos em um mundo em que nos dizem que todas as batalhas, perdidas ou não, são coisa do passado e que ter autonomia é uma questão de encontrar o modelo de saia mais adequado para a próxima entrevista de trabalho?

A oficina "Feminismo e nova geração política"' reuniu uma centena de pessoas em torno das experiências de jovens feministas da América Latina e da Europa e está certamente entre os debates políticos mais importantes realizados no Acampamento. $O$ encontro de experiências foi nosso ponto de partida para refletir sobre a construção do movimento de mulheres e do feminismo sob o ponto de vista da juventude. A juventude a que se refere o Acampamento vive em um mundo que nunca na história foi tão inseguro e tão desigual: um mundo de privação e violência, de precarização social e do trabalho, do estreitamento das liberdades de circulação e expressão das pessoas, da privatização do conhecimento e das condições de vida e dignidade. Uma juventude que cresceu ouvindo notícias do fim da história, do fim das utopias. Aquela juventude exortada a desenvolver seu 'marketing pessoal' entre taxas crescentes de desemprego e estratégias transnacionais de adensamento do apelo ao consumo.

Mas uma boa verdade sobre a geração de que estamos falando é que muitos desses e muitas dessas jovens, que cresceram nos anos 1980 e 1990 ouvindo as promessas do neoliberalismo e hoje assistem pela televisão aos discursos de George Bush sobre justiça e liberdade, conhecem o gosto amargo da mentira. A ascensão inegável de um movimento

\footnotetext{
${ }^{1}$ Elsa BEAULIEU, 2003.
} 
de movimentos contrário aos projetos globais de guerra e mercantilização da vida tem como protagonista também uma nova geração de militantes que, rebelando-se contra a mentira, buscaram sua voz política nas ruas, insurgindo-se contra a aplicação das políticas neoliberais por parte de governos locais e nacionais ou organizando protestos massivos contra as cúpulas das instituições do capitalismo globalizado. Essa geração, que vem sendo identificada como protagonista do movimento antiglobalização, se expressa em uma grande diversidade de percursos de ação e organização, através das mobilizações de massa, das redes de informação, dos organismos de comunicação autônomos (jornais, fanzines, rádios livres e sítios na Internet), da ação direta não violenta, da desobediência, da organização de coletivos radicais independentes de partidos políticos, de juventudes partidárias dispostas a arriscar seus limites institucionais, de grupos de artistas militantes, das greves estudantis e das ações de educação popular, entre outras formas.

Foram essas as juventudes que estiveram em Porto Alegre, que se referem a Porto Alegre, e constituem talvez a parte mais rica, crítica e paradoxalmente sub-representada da construção do Fórum Social Mundial que conhecemos hoje.

E lá estão as jovens mulheres mobilizadas mundo afora, organizando manifestações estudantis, ocupações, ativas nas comunidades da cultura Hip Hop das metrópoles brasileiras, nos coletivos anticapitalistas autônomos, nas juventudes dos partidos, nas paradas do orgulho LGBT pelo mundo, nos grupos piqueteros na Argentina...

O encontro no Acampamento revelou como na experiência dessas jovens se atualizam e renovam as questões fundamentais da organização do movimento de mulheres. Como, por exemplo, fazer política em movimentos de jovens homens e mulheres se, como nos contava Isabel, do Rio de Janeiro, as poucas mulheres a falar em uma reunião da União Nacional dos Estudantes arriscam ser recebidas com assobios e comentários engraçadinhos? Como nos afirmar feministas quando, como as jovens Silvia e Mariana, escolhemos fazer políica ao lado das mulheres que organizam refeitórios populares nas periferias de Buenos Aires, e nos sentimos distantes do que andaram discutindo os feminismos nos últimos anos?

A partir dessas e de outras vivências, às quais nem todas sobrevivem politicamente, é que muitas jovens começam a se dar conta de que existe alguma coisa de específico na realidade de sermos mulheres, a ganhar consciência da permanência da desigualdade de gênero e da opressão sexista. Nesse tipo de situação concreta, as jovens são capazes de apreender as novas formas complexas sob as quais a desigualdade se apresenta na experiência de sua geração, experimentam o desejo e a possibilidade de uma renovação das linguagens de resistência e reivindicação, de organizar-se e lutar enquanto mulheres, de apropriar-se do feminismo e reinventá-lo.

Desde o primeiro FSM o Acampamento foi construído como um espaço identificado com "o movimento internacional que vai de Chiapas a Seattle, de Genova a Porto Alegre". São muitas as jovens que hoje se envolvem nas manifestações locais e internacionais da nova onda de mobilização e politização que deságua nos Fóruns Sociais. Essas jovens são portadoras de um feminismo renovado porque precisam responder continuamente a desafios históricos que se colocam hoje não apenas para o feminismo, mas também para o conjunto dos projetos emancipatórios dos quais o 'movimento de movimentos' pretende ser canal de convergência. Certamente mais do que no ambiente acadêmico dos estudos de gênero ou nas estruturas institucionais das ONGs, é no embate de jovens militantes do movimento global para constituir-se como uma nova geração política que podemos hoje encontrar as jovens interessadas em levar adiante a organização e o projeto emancipatório das mulheres.

${ }^{2}$ Convocatória "Por uma rede de resistência global para o uso das novas gerações políticas", Iançada no III Acampamento Intercontinental da Juventude, em Porto Alegre, em janeiro de 2003, (MOVIMENTOS..., 2003). 


\section{Companheiras e companheiros}

E, como feministas, qual é o nosso espaço no movimento de movimentos? Se estamos sempre prontas a trabalhar pela agenda do movimento global, por que, como nos contou Elisa, vinda de Roma, o vigoroso movimento italiano não responde com a mesma prontidão quando precisamos sair às ruas contra uma lei que confere personalidade jurídica ao feto e ameaça o direito ao aborto que as mulheres conquistaram naquele país?

Um outro desafio das jovens na construção da nova geração políica de que são parte é afirmar o feminismo como dimensão fundamental da prática dos movimentos e dos projetos de um outro mundo possível para todas e todos. Isso não é uma coisa mais simples de se fazer entre jovens do que entre 'adultos', como poderiam fazer pensar as freqüentes naturalizações da rebeldia da juventude e o mito de que todo jovem tem 'a cabeça aberta'. Os jovens, convencidos do caráter 'novo' atribuído a seus princípios de ação e organização ou vaidosos da 'horizontalidade' das relações estabelecidas em seus grupos e movimentos, se recusam muitas vezes a admitir que exista entre eles, maculando sua capacidade de inovação, uma coisa tão 'velha' como o machismo. A ignorância em relação às questões das mulheres e ao feminismo é profunda e não é raro encontrar jovens mulheres e homens que não entendam do que estamos falando se hoje 'homens e mulheres já são iguais'. Outros, quando ouvem falar de feminismo, simplesmente morrem de medo de serem acusados e preferem evitar $o$ assunto.

A situação das meninas é particularmente delicada quando não há grupos de mulheres organizadas capazes de responder coletivamente às situações discriminatórias e pelo fato de que a importância da autonomia em relação aos homens freqüentemente não é vista como necessidade evidente. Iniciativas de auto-organização das mulheres, que como sabemos podem ter impacto rápido e profundo sobre as relações nos espaços mistos, são freqüentemente desqualificadas. As meninas que cobram igualdade de tratamento ou propõem dinâmicas que favoreçam a participação das mulheres podem ser facilmente acusadas de estar criando caso à toa ou simplesmente de estar 'querendo aparecer'. Também acontece de os grupos de jovens que se organizam sobre 'questões de gênero' terminarem afastados da discussão política geral ou considerados meros apêndices decorativos das estruturas burocráticas.

\section{"Unidas para ser rebeldes" ${ }^{3}$}

A experiência da Marcha Mundial das Mulheres no Acampamento da Juventude reafirmou a capacidade das jovens de criar contrapontos e desafiar essas limitações. A oficina "Pixação crítica e libertação de cartazes publicitários" discutiu as representações sexistas das mulheres no espaço público e nas mídias, a partir da aplicação de um "tratamento pictórico de choque" ${ }^{4}$ sobre cópias de cartazes publicitários. O ponto culminante desse exercício foi a decisão do grupo de jovens mulheres de realizar imediatamente uma manifestação feminista para denunciar o assédio e a violência contra as mulheres que ocorria dentro da Cidade das Cidades. As participantes inventaram ali mesmo o slogan "A violência contra a mulher não é o mundo que a gente quer" - para dizer a nossos companheiros que não se constroem espaços de liberdade sem igualdade entre mulheres e homens. Tiveram que se afirmar para tomar os tambores das mãos dos

\footnotetext{
${ }^{3}$ Título do $1^{\circ}$ Encontro de Jovens Feministas, realizado na Universidade de Montreal em setembro de 2003 , com apoio da Federação das Mulheres de Quebéc.

${ }^{4}$ Dominique FOUFELLE, 2003.
} 
meninos e convencê-los a diluir-se em uma manifestação de meninas. Exibindo os cartazes pintados e as bandeiras da Marcha Mundial das Mulheres, ao som dos tambores e das palavras de ordem, essa manifestação espontânea - forte e ritmada - foi recebida com alguma surpresa, mas também com aplausos, e cresceu animando o Acampamento. Mais uma vez foi uma experiência formadora, especialmente no quesito de questionar a ordem social em praça pública, ainda que em escala reduzida (ou nem tanto - muitos municípios por aí não têm a população de 30 mil pessoas que circulava pelo acampamento...).

\section{A juventude do feminismo}

Esse tipo de intervenção direta, de ocupação do espaço público, que dispensa a mediação institucional e que em geral caracteriza a disposição militante das jovens, dá sentido concreto ao objetivo colocado pela aposta da Marcha Mundial das Mulheres em estar em todos os cantos do FSM (oposição à idéia de circunscrever a questão de gênero a momentos e espaços 'específicos'): é necessário interpelar não apenas as 'autoridades competentes', mas também as práticas, os códigos, a consciência supostamente progressista daqueles que são nossos companheiros na luta cotidiana por um outro mundo possível. Essa postura emerge em diversos momentos do debate e da ação das jovens que estão construindo o feminismo hoje e deve contaminar o movimento de mulheres que pretenda responder a novas e velhas contradições.

Os Fóruns Sociais são momentos importantes para fortalecer o trabalho das jovens que lutam para levar o debate feminista dentro dos movimentos sociais, são momentos também de coordenar e trocar idéias e práticas políticas, de criar os espaços que merecem todas a jovens que a cada dia se descobrem mais feministas do que podiam imaginar. $A$ experiência de 2003 no Acampamento da Juventude aponta para as lacunas de uma ausência prolongada do feminismo e espaços de juventude. Mas também nos dá a certeza de que o próprio Acampamento, que se afirmou como laboratório de um mundo novo e expressão da geração que se propõe a construí-lo, já é mais feminista do que antes. $O$ mérito desse novo patamar de participação das mulheres em uma das dimensões mais promissoras do 'processo fórum' é de cada uma das jovens que se aventuraram a fazer barulho e ocupar as ruas com criatividade e irreverência. A Marcha Mundial das Mulheres segue buscando responder, primeiro, à necessidade de um instrumento coletivo que dê voz às iniciativas de meninas corajosas que freqüentemente permanecem incomunicáveis; segundo, à necessidade de inventar as formas de expressão do feminismo na experiência social e política particular das jovens do nosso tempo.

\section{Referências bibliográficas}

BEAULIEU, Elsa. "Feminismo e nova geração política". Memória do Fórum Social Mundial 2003. Disponível em: www.forumsocialmundial.org.br. 2003.

COCCIA, Elisa; DANILO, Corradi. "Um acampamento permanente". Memória do Fórum Social Mundial 2003. Disponível em: www.forumsocialmundial.org.br. 2003.

FOUFELLE, Dominique. "Do lado das jovens". Disponível em: www.penelopes.org. Acesso em: 26 jan. 2003.

LELIÈVRE, Colette. "Mulheres jovens no FSM 2003". Disponível em: www.cybersolidaires.org. Acesso em: 24 jan. 2003.

MOVIMENTOS Reunidos no III Acampamento Intercontinental da Juventude FSM 2003. "Convocatória 'Por uma rede de resistência global para o uso das novas gerações políticas'”. Disponível em: www.movsoc.org. 2003. 
Young feminists in motion: the World March of Women in the III Intercontinental Youth Camp Abstract: The proposal of this text is to present the questions raised by the World March of Women participation in the III Intercontinental Youth Camp. The activities and actions put forward by young feminists from all continents reveal that the experiences of this new political generation update and renew the fundamental questions of womens movements organising.

Key words: youth, feminism, new political generation, anti-globalization movement. 